\title{
Inhibición de bacterias patógenas por bacterias acidolácticas en quesos de cabra
}

\author{
Inhibition of patogenic bacteria by lactic acid bacteria in goat \\ cheeses
}

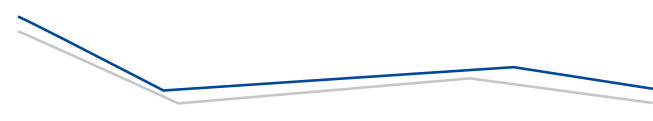

Dolores Gabriela Martínez-Vázquez*, Blanca Liliana Narvaéz-Guillén*, Armando Robledo-Olivo*, Ana Verónica Charles-Rodríguez*, Alma Leticia Martínez-Herrera*, Sarahí del Carmen Rangel-Ortega*®

Martínez-Vázquez, D. G., Narvaéz-Guillén, B. L., Robledo-Olivo, A., Charles-Rodríguez, A. V., Martínez-Herrera, A. L., \& Rangel-Ortega, S. C. (2020). Inhibición de bacterias patógenas por bacterias acidolácticas en quesos de cabra. Investigación y Ciencia de la Universidad Autónoma de Aguascalientes, 28(81), 24-31.

RESUMEN

Los quesos artesanales son reconocidos en el mundo por sus nutrientes y características sensoriales. Son elaborados manualmente en la pequeña industria con leche no sometida a tratamiento térmico que disminuya la flora microbiana, carentes casi siempre de control de calidad. Durante la presente investigación se midió la capacidad de inhibición de dos cepas de bacterias acidolácticas (BAL) aisladas en un estudio previo, conocidas como QR y QJ sobre las bacterias patógenas Escherichia coli y Salmonella. Todos los microorganismos anteriores fueron inoculados en quesos elaborados con leche de cabra pasteurizada. Posteriormente los quesos pasaron por un periodo de maduración y al término de este se realizaron conteos de UFC/g. Se logró una disminución en el número de ambos patógenos. La cepa QJ presentó mayor

Palabras clave: quesos artesanales; patógenos; bacterias acidolácticas; inhibición; pasteurización; maduración.

Keywords: artisanal cheeses; pathogens; lactic acid bacteria; inhibition; pasteurization; ripening.

Recibido: 14 de diciembre de 2019, Aceptado: 24 de septiembre de 2020

* Departamento de Ciencia y Tecnología de Alimentos, Universidad Autónoma Agraria Antonio Narro. Calz. Antonio Narro 1923, Buenavista, C. P. 25315, Saltillo, Coahuila, México. Correo electrónico: gabriela. martinez@uaaan.edu.mx; narvaez_lili@hotmail.com; armando.robledo@ vaaan.edu.mx; ana.charles@uaaan.edu.mx; amarher@uaaan.edu.mx sarahi.rangel@uaaan.edu.mx ORCID: http://orcid.org/0000-0003-1221-

7699; http://orcid.org/0000-0002-9948-2219; http://orcid.org/00000002-6604-7771; http://orcid.org/0000-0002-3863-9075; http://orcid. org/000-0002-7722-9925; http://orcid.org/0000-0003-2201-107X

Autora para correspondencia inhibición contra Escherichia coli, mientras que la cepa QR contra Salmonella. Ambas cepas mostraron su mejor desempeño inhibitorio a los seis días de maduración.

ABSTRACI

Artisanal cheeses are recognized in the word for their nutrients and sensorial characteristics, made manually by the small industry whit milk that has not been subjected to any thermal treatment that reduce microbial flora, always lacking in quality control. During this investigation the inhibition capacity of two strain of lactic acid bacteria (LAB) isolated in a previous study, known as $Q R$ and $Q J$ on two pathogenic bacteria Escherichia coli and Salmonella was measured. All the previous microorganisms were inoculated in cheeses made with pasteurized goat's milk. Subsequently the cheeses were left ripening and at the end of this period $\mathrm{CFU} / \mathrm{g}$ count were made. A decrease in number of both pathogens was achieve. The QJ strain showed greater inhibition against Escherichia coli, while, QR strain against Salmonella, both LAB strains showed their best inhibition activity at 6 days of ripening.

\section{INTRODUCCIÓN}

Los quesos artesanales de cabra son productos que gozan de excelente calidad nutricional y particularmente sensorial como resultado del proceso y materia prima (leche sin pasteurizar) gracias a las BAL presentes; sin embargo, la calidad sanitaria de estos productos se encuentra comprometida por la presencia de bacterias patógenas que no son 
eliminadas de la leche con la que se elaboran. Lo anterior desencadena enfermedades de transmisión alimentaria (ETA) en quienes los consumen (Alvarado Rivas, Chacón Rueda, Otoniel Rojas, Guerrero Cárdenas, \& López Corcuera, 2007; Morales-Pablo, Ávalos de la Cruz, Leyva-Ruelas, \& Ybarra-Moncada, 2012).

Los microorganismos patógenos asociados con la generación de ETA procedentes de quesos artesanales son E. coli, Salmonella spp., Staphylococcus aureus y Listeria Monocytogenes principalmente; la presencia de estos obedece a un mal protocolo de higiene en el proceso de elaboración, así como al empleo de leche bronca (Fuentes Fanegas et al., 2017). En los últimos años las BAL han sido estudiadas por su potencial para formar cultivos iniciadores (Hayaloglu, Guven, Fox, \& McSweeney, 2005), ya que algunas de sus propiedades tecnológicas son la actividad antomicrobiana, conservadora, probiótica; gracias a sus péptidos poseen propiedades metabólicas.

Morfológicamente las BAL son cocos o bacilos, positivos a la prueba de gram y negativas a las pruebas de oxidasa y catalasa, anaeróbicas, microaerófilas y productoras de ácido láctico como principal metabolito por la fermentación de la lactosa (Carr, Chill, \& Maida, 2002; Vázquez, Suárez, \& Zapata, 2009). Las BAL crecen en un rango de $\mathrm{pH}$ entre 3.2 y 9.6 y sobreviven en medios donde la actividad por los ácidos orgánicos no se lo permitiría a otras bacterias (Carr et al., 2002), con ello desarrollan la capacidad de inhibir microorganismos alterantes o patógenos. La capacidad de inhibición de las BAL se debe en primer instancia a la formación de ácidos orgánicos como el ácido láctico y el acético que hacen descender el pH, además de la competencia por el sustrato del medio; asimismo, forman tanto compuestos no proteicos como proteicos de síntesis ribosomal conocidos como bacteriosinas (Casaus Lara, Hernández Cruza, \& Cintas Izarra, 2000).

Se ha demostrado que las BAL originarias de quesos artesanales tienen capacidad de controlar el crecimiento de bacterias patógenas. Fuentes Fanegas et al. (2017) estudiaron la capacidad de inhibición de cepas de BAL autóctonas del queso doble crema y quesillo frente al crecimiento in vitro de Salmonella enterica subsp. enterica serovar Typhimurium ATCC 13311 y Listeria monocytogenes ATCC 7644 por el método de perforación de placa, con mayores niveles de inhibición contra Listeria monocytogenes ATCC 7644.

Otro estudio similar realizado por Martín del Campo M., Gómez H. y Alaníz de la O. (2008) demostró la capacidad antagónica de cepas aisladas de quesos frescos artesanales (adobera y panela) contra Listeria monocytogenes, Staphylococcus aureus, Streptococcus pyogenes y Salmonella agona; Listeria monocytogenes fue el patógeno que presentó mayor inhibición por las BAL usando la técnica de inoculación por picadura; el resto de los patógenos Gram positivos fueron inhibidos a excepción de Salmonella agona (Gram negativa).

La inoculación de BAL con propiedades antimicrobianas aisladas del propio queso artesanal de cabra se presenta como una posibilidad de disminuir la cantidad de bacterias patógenas al mejorar su calidad sanitaria y al resguardar los sabores propios del queso artesanal de cabra (Mago, Sanabria, Cova, Alvarado, \& Durán, 2015). En un estudio previo realizado por Narváez Guillén et al. (2017) fueron aisladas en un medio selectivo (MRS) 21 cepas de BAL del queso artesanal de cabra elaborado por pequeños productores al Sur Este de Coahuila, México. Las cepas de BAL fueron caracterizadas morfológicamente, todas ellas fueron positivas a la tinción de Gram y catalasa negativa.

Las cepas fueron también sometidas a pruebas de producción de ácido láctico, producción de aromas con notas lácteas, producción de $\mathrm{CO}_{2}$ y se probó la actividad inhibitoria in vitro de las 21 cepas frente a E. coli, Salmonella y Staphylococcus aureus por la técnica de difusión en hoyo. De las cepas con mayor inhibición frente a Salmonella y $E$. coli fueron QJ y $Q R$, que adicionalmente presentaron aromas con notas lácticas. Las 21 cepas se comportaron estadísticamente similares al inhibir a Staphylococcus aureus.

El presente estudio se centró en evaluar la capacidad de las dos cepas de BAL, nombradas como QJ y QR en el estudio previo de Narváez Guillén et al. (2017), así como en su combinación para inhibir el número poblacional de E. coli y Salmonella en quesos de leche pasteurizada de cabra. 
issn 1665-4412, e-issn 2521-9758

Martínez-Vázquez, D. G., Narvaéz-Guillén, B. L., Robledo-Olivo, A., Charles-Rodríguez, A. V.,

26

Martínez-Herrera, A. L., \& Rangel-Ortega, S. C.
MATERIALES Y MÉTODOS

\section{Viabilización de las BAL y bacterias patógenas}

Se utilizaron dos cepas de BAL de un estudio anterior (Narváez Guillén et al., 2017) identificadas como QJ y QR, así como cepas patógenas de Salmonella y E. coli. Las BAL se reactivaron en caldo MRS (Man, Rogosa y Sharpe); Salmonella y E. coli en caldo nutritivo, todas ellas en proporción de $1 \% \mathrm{v} / \mathrm{v}$ por triplicado y se incubaron a $32{ }^{\circ} \mathrm{C}$ de 24 a 32 h (Guerrero, Muset, \& Pacheco, 1997).

\section{Caracterización de BAL y bacterias patógenas}

Después del crecimiento celular las cepas se sembraron en cajas Petri por el método de estría cruzada en agar MRS para BAL y en agar nutritivo para las bacterias patógenas. Se incubaron a 32 ${ }^{\circ} \mathrm{C}$ entre 24 y 32 h y se observó crecimiento colonial característico de cada cepa. Se utilizó tinción de Gram con cada cepa (López Jácome et al., 2014), así como prueba de la catalasa (Ruiz Ruiz, 2010).

\section{Crecimiento de BAL y bacterias patógenas}

La determinación de la curva de crecimiento de cada microorganismo empleado en esta investigación se realizó mediante densidad óptica de la masa celular presente en medio líquido. Se empleó caldo MRS para las BAL (QR y QJ) y caldo nutritivo para las bacterias patógenas (Salmonella y E. coli), ambos inoculados con el respectivo microorganismo a una proporción de $1 \% \mathrm{v} / \mathrm{v}$ por triplicado. Las condiciones de incubación fueron semejantes a las antes mencionadas.

Se tomaron lecturas en lapsos de $1 \mathrm{~h}$ a $540 \mathrm{~nm}$. La medición se detuvo hasta observar el inicio de la fase estacionaria para todos los microorganismos (Díaz, 2011). Cuando cada cepa alcanzó el punto medio de la fase exponencial se realizaron conteos coloniales en placa. Se siguió la metodología de la NOM-110-SSA 1-1994 (SSA, 10 de mayo de 1995) para la preparación de las diluciones seriadas y para contabilizar las colonias en placa la metodología de la NOM-092-SSA 1-1994 (SSA, 12 de diciembre de 1995), modificando los agares (para las BAL se empleó el agar MRS, para Salmonella agar Salmonella Shigella y para E. coli agar MacConkey. Las condiciones de incubación fueron las anteriormente establecidas.

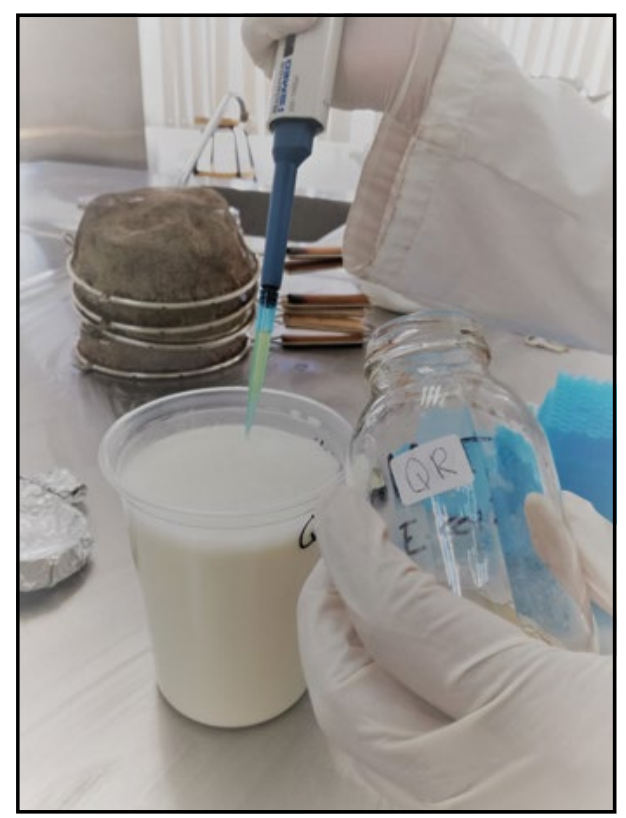

Figura 1. Proceso de inoculación de la leche pasteurizada con BAL.

Fotografía del equipo de investigación

\section{Elaboración de quesos de cabra inoculados con BAL y bacterias patógenas}

La elaboración de quesos inoculados se llevó a cabo de acuerdo con la metodología descrita por Narváez Guillén et al. (2017). Se realizaron ocho tratamientos con diseño ortogonal Taguchi (tabla 1). La elaboración de quesos fue a pequeña escala. Para cada tratamiento se empleó 11 de leche y moldes de $6 \mathrm{~cm}$ de diámetro. El proceso inició con el colado de la leche usando mantas de cielo, seguido de una pasteurización rápida a $72^{\circ} \mathrm{C} / 1$ min y posterior enfriamiento a $35^{\circ} \mathrm{C}$. Después la leche fue inoculada $5 \% \mathrm{v} / \mathrm{v}$ con la BAL correspondiente (en tratamientos con ambas cepas de BAL fueron inoculados con $2.5 \%$ $\checkmark / v$ de cada bacteria para completar la proporción) y $2.5 \% \mathrm{v} / \mathrm{v}$ de la bacteria patógena correspondiente, como se muestra en la figura 1.

El cuajado de la leche se realizó con cuajo comercial Cuamex siguiendo las instrucciones del producto. La leche se reposó por $30 \mathrm{~min}$. Transcurrido el tiempo se realizó el corte y desuerado, se añadió sal a una proporción de $3 \mathrm{~g} / \mathrm{l}$ de leche, la cuajada fue moldeada en moldes previamente estériles, posteriormente los quesos se desenmoldaron y empacaron para llevarse a maduración de 3 y 6 días (tomando en cuenta el tiempo promedio en que se 
consume un queso) a temperaturas de refrigeración $\left(4^{\circ} \mathrm{C}\right)$ según la tabla 1.

Tabla 1

Tratamaientos de elaboración de quesos

\begin{tabular}{|c|c|c|c|c|}
\hline \multirow{2}{*}{$\begin{array}{c}\text { Queso } \\
\text { (Tratamiento) }\end{array}$} & \multicolumn{2}{|c|}{ BAL } & \multirow{2}{*}{$\begin{array}{l}\text { Bacterias } \\
\text { Patógenas }\end{array}$} & \multirow{2}{*}{$\begin{array}{l}\text { Días en maduración } \\
\qquad\left(4^{\circ} \mathrm{C}\right)\end{array}$} \\
\hline & QR & QJ & & \\
\hline 1 & $\operatorname{Sin}$ & Sin & E. coli & 3 \\
\hline 2 & $\operatorname{Sin}$ & Con & E. coli & 6 \\
\hline 3 & Con & Sin & E. coli & 6 \\
\hline 4 & Con & Con & E. coli & 3 \\
\hline 5 & $\operatorname{Sin}$ & $\operatorname{Sin}$ & Salmonella & 3 \\
\hline 6 & Sin & Con & Salmonella & 6 \\
\hline 7 & Con & $\operatorname{Sin}$ & Salmonella & 6 \\
\hline 8 & Con & con & Salmonella & 3 \\
\hline
\end{tabular}

Nota: Elaboración propia.

Conteo de BAL y bacterias patógenas en quesos inoculados después de la maduración

Transcurrido el tiempo de maduración se llevó acabo el recuento de unidades formadoras de colonias (UFC/g) de BAL, así como de bacterias patógenas para cada tratamiento bajo la metodología de conteo colonial antes citada para cada grupo de bacterias.

\section{Análisis de datos}

Los valores de UFC/g de BAL, así como de patógenos contabilizados para cada tratamiento fueron sometidos a un análisis de varianza de una vía ( $p \leq$ 0.05 ) y las medias de los tratamientos fueron sometidas a una prueba de Tukey en el paquete estadístico JMP.

\section{RESULTADOS}

\section{Caracterización de BAL y bacterias patógenas}

La morfología colonial que presentaron ambas cepas de BAL fueron colonias redondas color blanco cremoso. Salmonella presentó colonias redondas color rosa a rojo mientras que E.coli colonias redondas color rosa fucsia. QJ presentó morfología celular de bacilo gram positivo, QR cocobacilo gram positivo, mientras que Salmonella y E.coli presentaron una morfología celular de bacilo gram negativo. Ambas BAL reaccionaron negativamente a la prueba de la catalasa.

\section{Crecimiento de BAL y bacterias patógenas}

Los resultados obtenidos indican que para las bacterias ácido lácticas QJ y QR el inicio de la etapa de crecimiento exponencial se desarrolla a partir de las 3 y $4 \mathrm{~h}$, respectivamente. A las $7 \mathrm{~h}$ de incubación para QJ se encuentra la etapa de crecimiento exponencial antes de llegar a la fase estacionaria; en este punto se presenta una absorbancia de 0.819 (figura 2); la mismas condiciones para QR se presentan en el mismo periodo de tiempo con una absorbancia de 0.519 (figura 3).

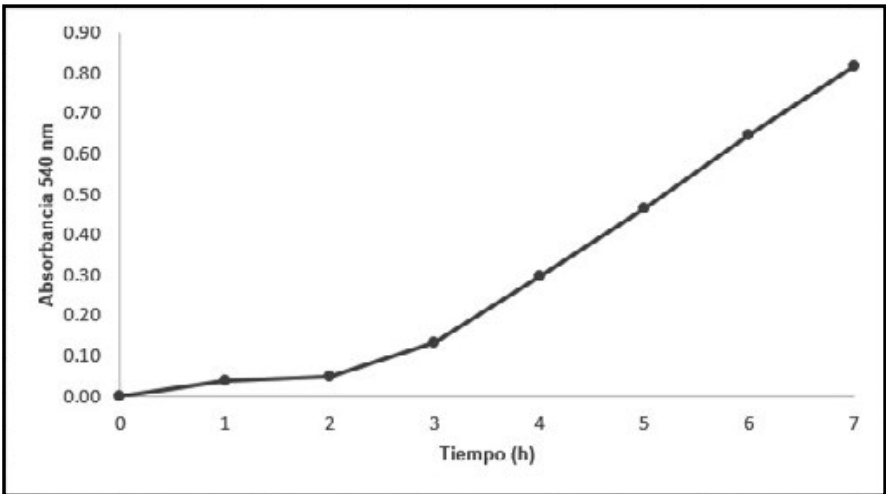

Figura 2. Curva de crecimiento de QJ. Elaboración propia.

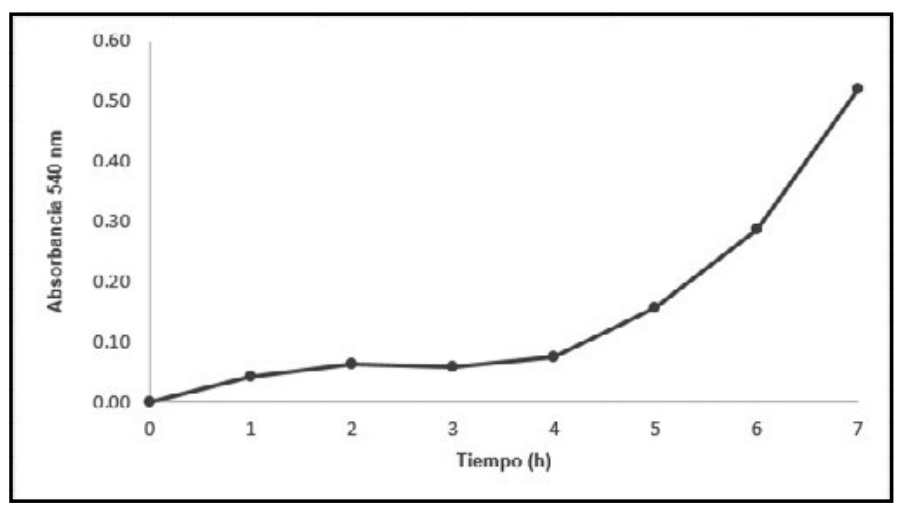

Figura 3. Curva de crecimiento de QR. Elaboración propia. 
issn 1665-4412, e-issn 2521-9758

Martínez-Vázquez, D. G., Narvaéz-Guillén, B. L. Robledo-Olivo, A., Charles-Rodríguez, A. V.,

28

Para Salmonella el crecimiento exponencial inicia en $3 \mathrm{~h}$ y a las $6 \mathrm{~h}$ de incubación (fase avanzada de crecimiento exponencial) presenta una absorbancia de 0.67 (figura 4 ). E. coli a las $5.5 \mathrm{~h}$ de incubación alcanza las mismas condiciones de crecimiento que las BAL y Salmonella, al registrar una absorbancia de 0.55 (figura 5).

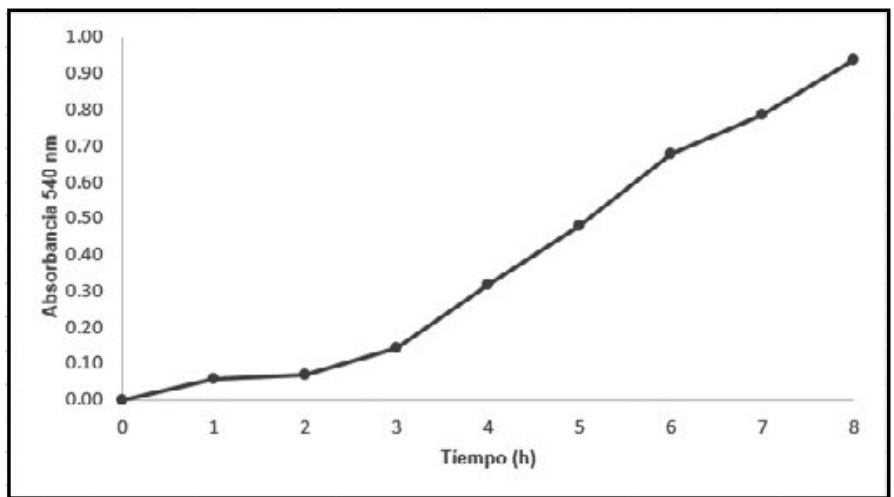

Figura 4. Curva de crecimiento de Salmonella.

Elaboración propia.

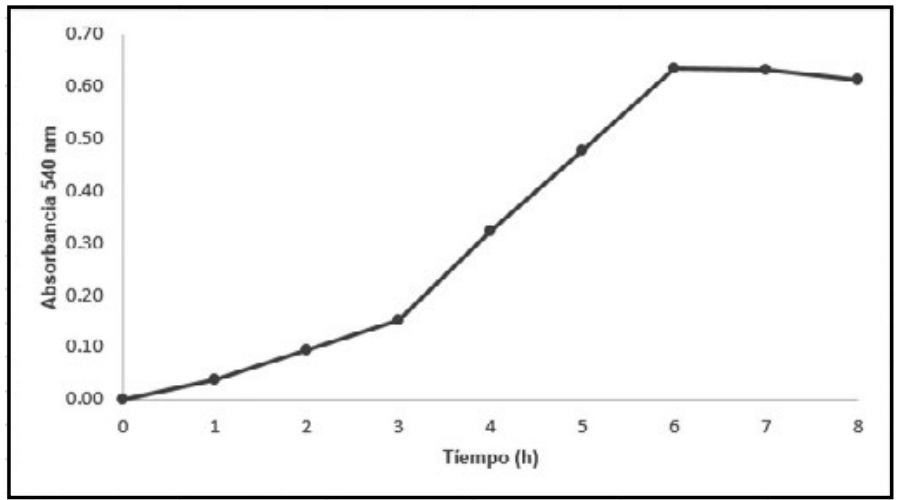

Figura 5. Curva de crecimiento de E. coli.

Elaboración propia.
Los resultados obtenidos expresados en UFC/ $\mathrm{ml}$ en el tiempo de crecimiento exponencial de los microorganismos fueron para QJ a las $6 \mathrm{~h} 8.5$ UFC $\log _{10} / \mathrm{ml}$, para QR a las 7 h 9.3 UFC Log $_{10} / \mathrm{ml}$. Las bacterias patógenas presentaron un crecimiento de $8.6 \mathrm{Log}_{10} \mathrm{UFC} / \mathrm{ml}$ para Salmonella y para E.coli de $8.4 \mathrm{Log}_{10} \mathrm{UFC} / \mathrm{ml}$, en $6 \mathrm{~h}$ y $5.5 \mathrm{~h}$, respectivamente (tabla 2).

\section{Elaboración de quesos inoculados con BAL y bacterias patógenas}

Se obtuvieron quesos de pasta uniforme de $6 \mathrm{~cm}$ de diámetro por $1.5 \mathrm{~cm}$ de alto, de color y olor característicos al queso de cabra (figura 6).

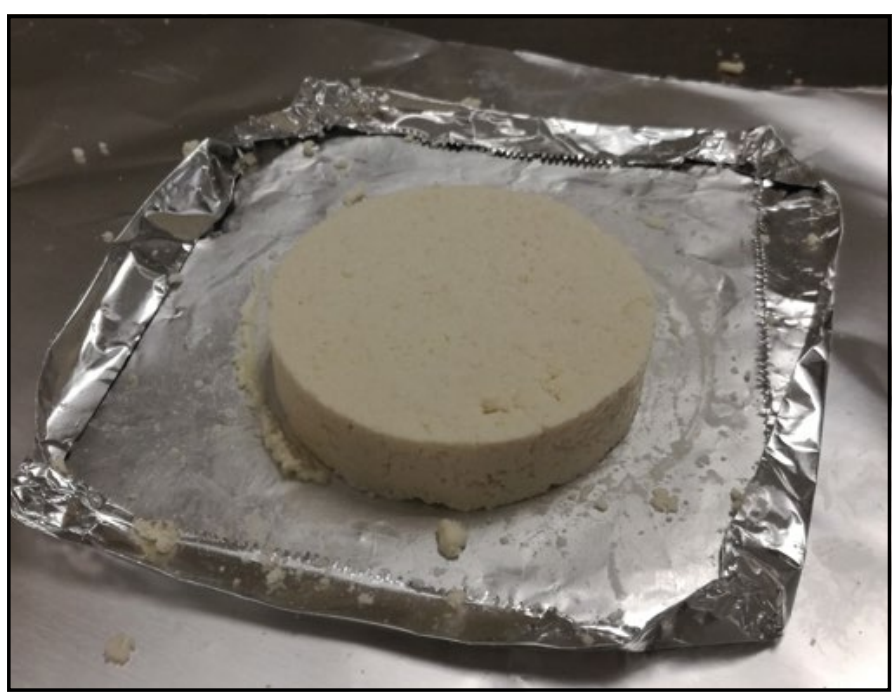

Figura 6. Queso de cabra inoculado con BAL y bacterias patógenas.

Fotografía del equipo de investigación.

Tabla 2

Conteo colonial de BAL y bacterias patógenas en fase de crecimiento exponencial

\begin{tabular}{ccc}
\hline Microorganismo & Absorbancia $(540 \mathrm{~nm}) /$ tiempo $(\mathrm{h})$ & UFC log $10 / \mathrm{ml}$ \\
\hline QJ & $0.64 / 6$ & 9.3 \\
QR & $0.51 / 7$ & 8.5 \\
E. coli & $5.46 / 5.5$ & 8.4 \\
Salmonella & $0.69 / 6$ & 8.6 \\
\hline
\end{tabular}

Nota: Elaboración propia. 
Recuento de BAL y bacterias patógenas en quesos después del periodo de maduración

Los resultados obtenidos del conteo de BAL y E.coli para los tratamientos 1-4 se presentan en la figura 7 , donde se observó diferencia significativa respecto al número de BAL, así como de E. coli. El tratamiento 3 (inoculado con QJ) presentó la mayor cantidad de $\mathrm{BAL}$, registrando $9.2 \mathrm{Log}{ }_{10} \mathrm{UFC} / \mathrm{g}$, seguido de los tratamientos 1 y 2 que fueron estadísticamente semejantes con 8.7 y 8.1 Log $_{10} U \mathrm{UCC} / \mathrm{g}$, respectivamente. Por último, el tratamiento 4 (inoculado con ambas cepas QJ y QR) presentó la menor cantidad de BAL, $7.9 \mathrm{Log}{ }_{10} \mathrm{UFC} / \mathrm{g}$. Estos mismos tratamientos en relación con la cuenta de E. coli, el tratamiento 3, presentó mayor presencia del patógeno; $7.9 \mathrm{Log}{ }_{10} \mathrm{UFC} / \mathrm{g}$, seguido de los tratamientos 1 y 4 (7.1 y $5.3 \mathrm{Log}_{10} \mathrm{UFC} / \mathrm{g}$, respectivamente) y finalmente el tratamiento 2 con $4.5 \mathrm{Log}{ }_{10} \mathrm{UFC} / \mathrm{g}$. Fue en este último tratamiento donde se observó la mayor inhibición de E.coli a pesar de no ser el tratamiento con la mayor cuenta de BAL.

Del conteo de BAL para los tratamientos $5,6,7$ y 8 inoculados con Salmonella, según se muestra en la figura 8, el tratamiento 5 obtuvo una cuenta celular de $8.6 \mathrm{Log}_{10} \mathrm{UFC} / \mathrm{g}$ al presentar la mayor cantidad de BAL, seguido de los tratamientos 6 y 8 con 8.5 $\log _{10}$ UFC/g en ambos tratamientos estadísticamente semejantes; por último, el tratamiento 7 (inoculado con QJ) registró la menor cantidad de BAL, 7.9 $\mathrm{Log}_{10}$ UFC/g. Respecto a la inhibición de Salmonella en los tratamientos 5, 6, 7 y 8 después de la maduración, la mejor actividad se presentó en el tratamiento 7 con 5 Log ${ }_{10} U F C / g$, seguido de los tratamientos 5 y 8; por último el tratamiento 6 con 8, 8.1 y 9.1 Log ${ }_{10} U F C / g$, respectivamente.

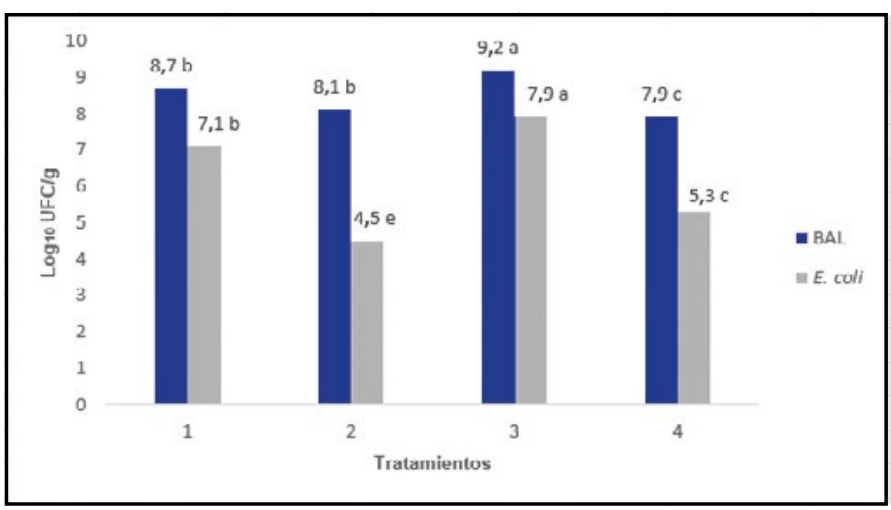

Figura 7. Conteo colonial de las BAL y E. coli en tratamientos 1-4. Elaboración propia.

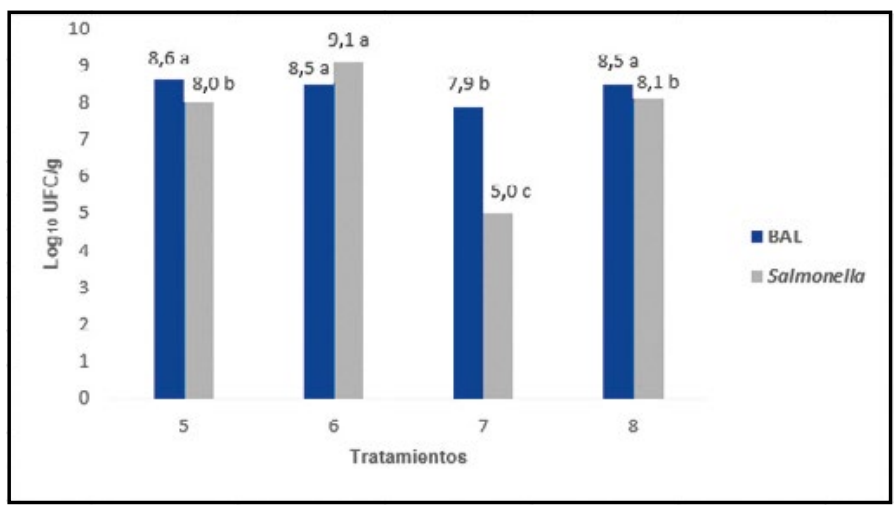

Figura 8. Conteo colonial de las BAL y Salmonella en tratamientos 5-8.

Elaboración propia.

\section{DISCUSIÓN}

La capacidad de inhibición de las BAL empleadas sobre bacterias patógenas mostró diferente comportamiento. QJ logró inhibir de manera significativa el crecimiento de E.coli a los 6 días de maduración en el tratamiento 2. Un desempeño similar mostró QR contra Salmonella en el mismo periodo de maduración del queso en el tratamiento 7. Narváez Guillén et al. (2017) estudiaron previamente tanto a QJ como a QR, entre otras cepas de BAL en su capacidad inhibitoria frente a E.coli y Salmonella mediante método in vitro por técnica de difusión en hoyo. Los valores reportados para la inhibición de E.coli fuerón desde 1.5 hasta $1.85 \mathrm{~cm}$ de $\varnothing$ de inhibición y QJ reportó $1.75 \mathrm{~cm}$ de $\varnothing$.

Respecto a Salmonella los valores de inhibición fueron entre 1.13 y $1.76 \mathrm{~cm}$ de $\varnothing$ de inhibición y $Q R$ reportó $1.73 \mathrm{~cm}$ de $\varnothing$. Aun cuando las unidades de los resultados del previo y presente estudios en los que se probó la inhibición de QR y QJ no son compatibles, existe congruencia en el comportamiento inhibitorio de estas BAL. Asimismo, en el estudio de Narváez Guillén et al. (2017) se presentó para QJ una producción en incremento de ácido láctico de 0.36 , 0.52 y $0.75 \%$ a las 12,24 y $48 \mathrm{~h}$, respectivamente. Según esta tendencia, podría explicarse la marcada inhibición en el tratamiento 2 inoculado con QJ y $E$. coli a seis días de maduración, ya que al elevarse la cantidad de ácido láctico y en consecuencia la disminución del $\mathrm{pH}$ se limita el crecimiento de E.coli (Heredia Castro, Hernández Mendoza, González Córdova, \& Vallejo Córdoba, 2017) pero favorece el desarrollo de BAL. 
Los valores de ácido láctico que alcanzó $Q R$ a los mismos periodos fueron $0.28,0.47$ y $0.89 \%$. De igual manera fueron valores en incremento que explican la conducta de la población, tanto de QR como de Salmonella en el tratamiento 7 (inoculado con QR y Salmonella a seis días de maduración) ante un medio con alta presencia de ácido láctico y como consecuencia bajo $\mathrm{pH}$, las posibilidades de sobrevivencia de Salmonella se vieron superadas por las de QR a medida que pasó el tiempo de maduración del queso.

Un factor que pudiera dar explicación a la especificidad de inhibición de QJ para E. coli y de QR para Salmonella es probablemente el tipo de bacteriosinas producidas por cada cepa de BAL, ya que se ha reportado a la pediocina producida por Lactococcus Lactis presente en quesos como inhibidora de E.coli y S. aureus (Heredia Castro et al., 2017); esto podría también aplicar para el efecto inhibitorio que mostró la combinacioón de QJ y $Q R$ hacia $E$. coli por el tipo de bacteriocinas producidas por cada BAL.

Por otra parte, Curvas Limón, Cruz Hernández y Belmares Cerda (2019), reportaron actividad inhibitoria contra E. coli y Salmonella Tiphy de las bacteriocinas producidas por dos cepas de BAL aisladas de leche de cabra, reportadas como LC1 y LC2. Los resultados se reportaron en $\mathrm{cm}$ de halos de inhibición. El mayor efecto ihibitorio se reportó para $E$. coli seguido de Salmonella Tiphy con un ligera diferencia, $1.32 \pm 0.03$ y $1.12 \pm 0.29 \mathrm{~cm}$ de $\varnothing$, respectivamente. En un estudio de Fuentes Fanegas et al. (2017) se probó el sobrenadante de BAL, aislados de queso doble crema y quesillo que se identificaron como Lactococcus lactis subsp. lactis y Lactobacilos fermentum con halos de inhibición de $0.29 \pm 0.017$ y $1.2 \pm 0.1$, respectivamente.

Al contrastar los resultados del presente trabajo con los de Curvas Limón et al. (2019) y Fuentes Fanegas et al. (2017), se encontró que presentan tendencias similares. Aunque en el presente estudio se probó el efecto inhibitorio con células de BAL debido a que además del efecto inhibitorio contra patógenos producen sabores, aromas y propiedades reológicas que enriquecen las características sensoriales del queso y en los otros dos estudios se probó el mismo efecto con bacteriosinas in vitro. Esto abre la posibilidad de explorar el mismo efecto inhibitorio con las bacteriosinas de QJ y QR y una posible aplicación de estas hacia diversos productos alimenticios.
En quesos artesanales como el de cabra es importante conservar las BAL presentes de manera natural en la leche, dado que son parte indispensable para la obtención de las propiedades que dan identidad sensorial al producto; sin embargo, es importante eliminar o disminuir la presencia de bacterias patógenas que representan un riesgo para la salud del consumidor, por ello se requiere mejorar las condiciones de higiene en la elaboración del producto (Alvarado Rivas et al., 2007); este trabajo propone inocular la leche con la que se elaboran los quesos mediante cepas de BAL propias del producto para disminuir microorganismos patógenos en los quesos artesanales de cabra sin sacrificar las características sensoriales.

CONCLUSIONES

Ambas cepas de BAL, QR y QJ demostraron inhibir el crecimiento de los microorganismos patógenos. La mayor inhibición de crecimiento de E. coli se logró con QJ y la de Salmonella con QR. La inhibición por la combinación de las dos cepas QJ y QR fué mas efectiva frente a $E$. coli. Estos resultados pueden ayudar a la formación de cultivos iniciadores para la elaboración de quesos de cabra que permitan obtener productos de alta calidad sensorial y microbiológica.

\section{REFERENCIAS}

- Alvarado Rivas, C., Chacón Rueda, Z., Otoniel Rojas, J., Guerrero Cárdenas, B., \& López Corcuera, G. (2007). Aislamiento. Identificación y caracterización de bacterias ácido lácticas de un queso venezolano ahumado andino artesanal. Su uso como cultivo iniciador. Revista Científica, $17(3), 301-308$.

- Carr, F. J., Chill, D., \& Maida, N. (2002). The lactic acid bacteria: A literature survey. Critical Reviews in Microbiology, 28(4), 281370. doi: 10.1080/1040-840291046759

- Casaus Lara, P., Hernández Cruza, P. E., \& Cintas Izarra, L. M. (2000). Actividad antimicrobiana de las bacterias lácticas (I y II). Alimentación, Equipos y Tecnología, 19(7), 109-124.

- Curvas Limón, R. B., Cruz Hernández, M., \& Belmares Cerda, R. E. (2019). Aislamiento, caracterización y evaluación antimicrobiana de bacterias a partir de leche de cabra. Investigación y Desarrollo en Ciencia y Tecnología de 
Alimentos, 4, 142-146.

- $\quad$ Díaz, C. (2011). Adherencia y colonización de Pseudomonas fluorescens sobre sustratos sólidos: Influencia de la topografía y composición química de la superficie (Tesis doctoral, pp. 103, 104, 105.). Repositorio institucional de la UNLP. doi: $10.35537 / 10915 / 2685$

- Fuentes Fanegas, M., Londoño Zapata, A., Durango Zuleta, M., Gutiérrez Buriticá, M., Ochoa Agudelo, S., \& Sepúlveda Valencia, J. (2017). Capacidad antimicrobiana de bacterias ácido lácticas autóctonas aisladas de queso doble crema y quesillo colombiano. Biotecnología en el Sector Agropecuario y Agroindustrial, 15(1), 45-55. Recuperado de https://revistas.unicauca.edu.co/index.php/biotecnologia/ article/view/534/637

- Guerrero, L., Muset, G., \& Pacheco, L. (1997). Evaluación de las actividades enzimáticas de cultivos comerciales usados para la elaboración de quesos. Revista Científica, 7(3), 209214.

- Hayaloglu, A. A., Guven, M., Fox, P. F., \& McSweeney, P. L. $H$. (2005). Influence of starters on chemical, biochemical, and sensory changes in turkish white-brined cheese during ripening. Journal of Dairy Science, $88(10), 3460-3474$. doi: 10.3168/jds.50022-0302(05)73030-7

- Heredia Castro, A., Hernández Mendoza, A., González Córdova, A. F., \& Vallejo Córdoba, B. (2017). Bacteriocinas de bacterias ácido lácticas: Mecanismos de acción y actividad antimicrobiana contra pátogenos en quesos. Interciencia, $42(6), 340-346$.

- López Jácome, L. E., Hernández Durán, M., Colín Castro, C. A., Ortega Peña, S., Cerón González, G., \& Franco Cendejas, R. (2014). Las tinciones básicas en el laboratorio de microbiología. Investigación en Discapacidad, 3(1),10-18.

- Mago, Y., Sanabria, N., Cova, A., Alvarado, C., \& Durán, L. (2015). Maduración de queso de cabra con cepa autóctona de Leuconostoc mesenteroides aislada de queso artesanal. Revista de la Facultad de Ciencias Veterinarias UCV, 56(1), 3-9.
- Martín del Campo M.,, C. I., Gómez H.,, H. E., \& Alaníz de la O., R. (2008). Bacterias ácido lácticas con capacidad antagónica y actividad bacteriocinogénica aisladas de quesos frescos. e-Gnosis, 6(5), 1-17.

- Morales-Pablo, R., Ávalos de la Cruz, D. A., Leyva-Ruelas, G., \& Ybarra-Moncada, M. C. (2012). Calidad bacteriológica de leche cruda de cabra producida en Miravalles, Puebla. Revista Mexicana de Ingenieria Química, 11 (1), 45-54.

- Narváez Guillén, B. L., Cruz Hernández, M. A., Hernández Centeno, F., Flores Verastegui, M. I. M., Martínez Vázquez, D. G., \& Rangel Ortega, S. C. (2017). Selección de bacterias ácido lácticas del queso artesanal de leche de cabra de Coahuila para su uso como cultivos iniciadores. Investigación y Ciencia de la Universidad Autónoma de Aguascalientes, $25(72), 45-52$.

- $\quad$ Ruiz Ruiz, F. (2010). Pruebas bioquímicas: Catalasa. Manual de Prácticas de Biología de Procariotas. Licenciatura en Biología [Protocolo de práctica en pdf]. Recuperado de https:// biolprocariotas.files.wordpress.com/2010/03/pract-1 12.pdf

- Secretaría de Salud. (10 de mayo de 1995). Norma Oficial Mexicana NOM-110-SSA1-1994, Bienes y servicios. Preparación y dilución de muestras de alimentos para su análisis microbiológico. Recuperado de http://www.salud. gob.mx/unidades/cdi/nom/110ssal4.html

(12 de diciembre de 1995). Norma Oficial Mexicana NOM-092-SSA1-1994, Bienes y servicios. Método para la cuenta de bacterias aerobias en placa. Diario Oficial de la Federación. Recuperado de https://www.dof.gob.mx/ nota_to_imagen_fs.php? codnota $=4886029 \&$ fecha $=12 / 12 / 19$ 95\&cod_diario $=209451$

- Vázquez M., S. M., Suárez M., H., \& Zapata B., S. (2009). Utilización de sustancias antimicrobianas producidas por bacterias ácido lácticas en la conservación de la carne. Revista Chilena de Nutrición, 36(1), 64-71. 